\title{
Antecedentes en la investigación sociodemográfica sobre las separaciones conyugales en Latinoamérica, 1980-2017
}

\section{A review of the sociodemographic research background on the union dissolution in Latin America, 1980-2017}

\author{
Fernando Ruiz-Vallejo* \\ Montserrat Solsona i Pairó**
}

\begin{abstract}
Resumen
El presente artículo tiene por objetivo sistematizar la literatura sociodemográfica sobre las separaciones conyugales en América Latina entre 1980 y 2017 a través de, por un lado, la identificación de las metodologías y las fuentes empleadas para su estudio, y, por otro, la documentación de los diferenciales abordados en estos trabajos. Los resultados permiten proponer tres narraciones subyacentes a la evolución del tema: a) los trabajos que analizan la separación conyugal como un inhibidor y/o promotor de la fecundidad; b) aquellos que la conciben como expresión de la modernización en el marco del debate sobre la segunda transición demográfica; y c) los que la perciben como un objeto propio de estudio.
\end{abstract}

Palabras clave: separación conyugal; divorcio; América Latina.

* Asociación Profamilia. Dirección: Calle 34, núm. 14-52, Bogotá, Colombia. Correo: fernando.ruiz@profamilia.org.co ORCID: https://orcid.org/0000-0003-1121-2562

** Universitat Autònoma de Barcelona. Dirección: Carrer de Ca n’Altayó, Edifici E2, Centre d'Estudis Demogràfics, 08193, Bellaterra, Barcelona, España. Correo: msolsona@ced.uab. cat ORCID: https://orcid.org/0000-0002-5613-672X

Nota de los autores: El artículo forma parte de la tesis La separación conyugal en Colombia, 1951-2015: geografias y biografias en clave de género, realizada por Fernando Ruiz-Vallejo en el doctorado en Demografía del Centre d'Estudis Demogràfics de la Universitat Autònoma de Barcelona, bajo la dirección de Montserrat Solosona y Albert Esteve.

Agradecimientos: Fernando Ruiz-Vallejo agradece al Departamento Nacional de Ciencias, Tecnología e Innovación (Colciencias) de Colombia por la beca recibida para realizar los estudios doctorales. Montserrat Solsona i Pairó agradece al Ministerio de Economía y Competitividad de España el financiamiento del proyecto "La custodia compartida después de una ruptura de unión: ¿qué contextos favorecen este paradigma emergente?” (2016-2020), del cual deriva parte de este artículo (Plan Estatal I+D, ref. CSO2016-78715-R). 


\begin{abstract}
The aim of this article is to systematize the sociodemographic literature on union dissolution in Latin America between 1980 and 2017 through, on the one hand, the identification of methodologies and sources used for their study, and another, the documentation of its differentials. The results allow proposing three narrations underlying the evolution of this topic: a) the works that analyze the union dissolution as an inhibitor and / or promoter of fertility; b) those who conceive it as an expression of modernization in the framework of the second demographic transition; and c) those who conceive it as an object of study itself.
\end{abstract}

Keywords: union dissolution; divorce; Latin America.

\title{
Introducción
}

El aumento de la separación conyugal es parte de una serie de amplios cambios experimentados por la familia en América Latina a lo largo del siglo $\mathrm{XX}$ e inicios del XXI, los cuales se expresan también en la reducción del tamaño de los hogares, el aumento de los hogares unipersonales y monoparentales -especialmente con jefatura femenina (Liu, Esteve, y Treviño, 2017)-, el retraso y la reducción de la intensidad de las uniones, y el aumento de las uniones libres, entre otros (Esteve, Lesthaeghe y Lopez-Gay, 2012; Fernández, 2010; García y Rojas, 2004). Además de ser un determinante de la dinámica familiar (Ojeda, 1989), las separaciones conyugales son un elemento central de los sistemas de nupcialidad. Éstos son entendidos como las normas y las instituciones sociales que guían la conformación de las familias.

En términos demográficos, los sistemas de nupcialidad se definen por cinco características, según la propuesta de Fussell y Palloni (2004). Tres de éstas se relacionan con el inicio de la vida en pareja: la intensidad, el calendario y el tipo de unión; y dos con su disolución: la intensidad de las separaciones conyugales y el inicio de las segundas o ulteriores uniones. Sin embargo, los mismos autores señalan la dificultad de contar con una radiografía completa de los sistemas de nupcialidad latinoamericanos al carecer de datos confiables sobre la disolución de las uniones.

A pesar de la relevancia de las separaciones conyugales en el análisis de los cambios demográficos, la escasez de trabajos en esta temática es evidente, especialmente cuando se compara con el volumen de investigaciones en otros aspectos de la nupcialidad, como el tipo de unión o los calendarios en la formación de la pareja (Cabella, 1998; Fussell y Palloni, 2004; García y Rojas, 2004; Rossetti, 1991). Ya desde los años ochenta, Goldman (1981) 
y Ojeda (1986) argumentaban que este vacío se debía, por una parte, a las restricciones de las fuentes oficiales para registrar las uniones disueltas y, por otra, a la importancia de las uniones libres como forma extendida de conyugalidad, de la cual no queda constancia tras su finalización.

El objetivo del presente artículo es sistematizar la literatura sociodemográfica sobre las separaciones conyugales en América Latina, en un intento por identificar la génesis y evolución del tema. Se propone realizar un inventario de las metodologías y de las fuentes empleadas en el estudio de la disolución, siguiendo ejercicios de sistematización similares (Spijker y Solsona, 2012). La exploración bibliográfica se realizó en bases de datos internacionales (Jstor y ScienceDirect) y regionales (Redalyc y Scielo). Estos trabajos abarcan el periodo 1980-2017 como criterio temporal, aunque se incluyeron referencias anteriores con fines de contextualización. También se consideraron investigaciones publicadas en formato de libro, capítulos de libros o tesis, referidas en los artículos científicos o recomendadas por expertos en el campo. Como palabras de búsqueda se usaron los términos divorcio, separación, separación conyugal, ruptura de unión, ruptura matrimonial, ruptura conyugal, disolución de la unión y disolución del matrimonio; aunado a los términos Latinoamérica, América Latina. ${ }^{1}$

En la presente revisión adoptamos el término separación conyugal para hacer referencia a las rupturas de las uniones estables, habiendo sido iniciadas éstas mediante un matrimonio institucional (religioso o civil) o a través de una unión libre, independientemente de si se transitó o no hacia un matrimonio. Esta consideración implica, a su vez, una mirada amplia del concepto conyugalidad en los términos propuestos por Pedro Quintín, quien entiende la relación conyugal como la cohabitación íntima continuada y socialmente reconocida, más allá de las expectativas de perdurabilidad de sus miembros (Quintín, 2008). En beneficio de la fluidez de la exposición, se usan de manera intercambiable los términos separación conyugal, ruptura o disolución de la unión.

Además de la presente introducción, el artículo tiene cinco apartados adicionales. En el primero se describen las narraciones sobre el divorcio y la separación conyugal, identificadas a partir de las motivaciones y principales preocupaciones de los trabajos analizados, que contextualizan los hallazgos en términos de estimaciones y factores asociados, correspondientes

${ }^{1}$ La búsqueda identificó 2674 resultados. A partir de la lectura de los títulos se filtraron 156 artículos relacionados con el tema de la revisión. Luego de la lectura de los resúmenes, se seleccionaron 29 artículos que cumplían los criterios de selección. Adicionalmente, se incluyeron 75 trabajos como resultado de la búsqueda intencionada complementaria. De esta manera, la revisión consideró 104 textos. 
al segundo y tercer apartados, respectivamente. Finalmente, en el cuarto y último apartado se presentan las conclusiones de la revisión, destacando los aportes y las líneas futuras de pesquisa.

\section{Las narraciones de la investigación sociodemográfica sobre la separación conyugal}

Se proponen tres relatos a partir de una interpretación propia de los trabajos revisados. Dichas narraciones actúan como sustrato de la producción sociodemográfica sobre la separación conyugal en América Latina.

\section{Las separaciones: ¿inhibidoras o promotoras de la fecundidad?}

En las décadas de los sesenta y setenta los estudiosos de los determinantes de la fecundidad también incluyeron a América Latina y al Caribe en sus investigaciones sobre la materia. Destacan los trabajos del Centro Latinoamericano y Caribeño de Demografía (Celade) de la Comisión Económica para América Latina (CEPAL), al implementar el Programa de Encuestas Comparativas de Fecundidad en América Latina (PECFAL) en áreas urbanas y rurales. El PECFAL-Urbano se llevó a cabo entre 1964 y 1966 en siete ciudades: Bogotá, Buenos Aires, Ciudad de México, Caracas, Ciudad de Panamá, Río de Janeiro y San José de Costa Rica. Por su parte, el PECFAL-Rural (1969-1970) incluyó información sobre áreas rurales de Colombia, Costa Rica, México y Perú (Rosero-Bixby, 1978). Así mismo, destacan los aportes de la Encuesta Mundial de Fecundidad, realizada entre 1970 y 1980 en trece países de la región.

Con base en las encuestas del PECFAL-Urbano, se analizó el peso de estos dos mecanismos en los niveles de fecundidad en seis ciudades latinoamericanas, identificando que, para las mujeres con mayor escolaridad o nivel socioeconómico, el tiempo de exposición perdido ante un embarazo por haberse disuelto una unión era más importante sobre la fecundidad total que para aquellas mujeres con condiciones económicas o educativas desfavorables (Downing y Yaukey, 1979). Un resultado similar fue constatado en San José de Costa Rica, donde se estimó que aproximadamente 10\% del periodo reproductivo en general, se había perdido por la ruptura de las uniones conyugales, siendo las pérdidas tres veces más altas para las mujeres provenientes de cohabitaciones en comparación con quienes habían tenido matrimonios formales (Onaka y Yaukey, 1973). 
Sin embargo, Downing y Yauke (1979) también identificaron el mecanismo "pronatalista" de la inestabilidad de la unión sobre la fecundidad. En su estudio, las uniones conformadas después de la disolución de la primera unión tenían mayor peso que el tiempo de exposición perdido entre dos uniones, incrementando así la paridad final respecto a quienes no experimentaban rupturas conyugales. Particularmente, este efecto se daba con mayor intensidad entre las mujeres de niveles socioeconómicos más bajos. Una asociación similar ya había sido encontrada previamente en Barbados, en donde se confirmó la relación positiva entre el número de parejas y el número de hijos nacidos vivos (Ebanks, George y Nobbe, 1974).

Después de los trabajos de los setenta, el estudio de la relación entre la separación conyugal y la fecundidad experimentó un periodo de silencio que duró hasta la primera década del año 2000, con la publicación de trabajos que revisitaban el tema. Tras el aumento de la disolución de las uniones en las últimas tres décadas del siglo pasado, crecía el volumen de personas separadas, se rejuvenecía la edad a la disolución, se elevaba la conformación de nuevas uniones $\mathrm{y}$, con ello, la probabilidad de tener nuevos hijos.

En Brasil, Leone y Hinde (2007), además de identificar que las mujeres con segundas o posteriores uniones presentaban mayor riesgo de tener hijos adicionales, confirman la relación positiva entre el riesgo de ruptura y el de nuevas concepciones (Leone y Hinde, 2007). En Colombia también se encontró una asociación positiva (Zamudio y Rubiano, 1991). En Uruguay, por el contrario, no se encontró ni un efecto depresor ni uno promotor de la disolución sobre la fecundidad. Este balance neutro se da como resultado de dos procesos: por un lado, la fecundidad de las mujeres uruguayas que experimentan la ruptura de su unión se ve compensada por los hijos tenidos en segundas o posteriores uniones; por otro, se observa que quienes tienen hijos después de la ruptura son justamente quienes se vuelven a unir, y que incluso cuando no se tienen estos hijos o se tienen pocos, es por la existencia de hijos en la primera unión (Fernández, 2017).

\section{Las separaciones como expresión de la modernización en el marco de la segunda transición demográfica}

Diversos trabajos destacan el aumento de la separación y el divorcio como uno de los principales cambios en la familia latinoamericana. Ariza y Oliveira (2001) consideran que, junto a la disolución de las uniones, el incremento de las uniones consensuales, la expansión de las familias con jefatura femenina y la flexibilización de algunos modelos de autoridad familiar 
como consecuencia de la incorporación de la mujer al mercado de trabajo, constituyen los principales ajustes de la familia en América Latina. Esta serie de tendencias ha llamado la atención de los investigadores, quienes tratan de explicar si dichas transformaciones son expresiones de una suerte de desinstitucionalización de la vida familiar dentro de procesos más amplios de individuación y autonomía personal propios de las sociedades contemporáneas. La teoría de la segunda transición demográfica (STD) (Van de Kaa, 2002; Lesthaeghe, 1995) ha sido un referente conceptual para algunos especialistas de la región. Se ha utilizado como herramienta analítica para comprender los cambios familiares y también como centro de debate en la validación de sus premisas bajo las particularidades históricas del caso latinoamericano.

Si bien la teoría de la STD tiene en cuenta diversos indicadores relacionados con los tipos de unión y de familias, la fecundidad y los cambios sociales, es el aumento de las tasas de divorcio experimentadas por Estados Unidos y los países escandinavos durante la década de 1950 lo que marca el inicio de una serie de cambios en los regímenes familiares más amplios (Lesthaeghe, 2010). El interés por explorar la pertinencia de la teoría de la STD en América Latina destaca en trabajos que reflejan en su título este debate, por ejemplo: "Buenos Aires y Montevideo: ¿dos orillas y una transición? La segunda transición demográfica en perspectiva biográfica" (Cabella, Peri y Street, 2005); "Dos décadas de transformaciones de la nupcialidad uruguaya. La convergencia hacia la segunda transición demográfica" (Cabella, 2009); "Fecundidad y familia en Colombia: ¿hacia una segunda transición demográfica?" (Flórez y Sánchez, 2013); "La segunda transición demográfica y el caso argentino" (Sana, 2001); y uno en el que participa el mismo Lesthaeghe, intitulado "The second demographic transition features in Latin America: The 2010 update" (Esteve, García-Roman, Lesthaeghe y Lopez-Gay, 2012).

Si bien las posiciones en el debate son diversas, un elemento común es el reconocimiento de la heterogeneidad de América Latina, tanto entre países como en el interior de cada uno de ellos, resultado de las desigualdades en la distribución de la riqueza y otros elementos fundamentales, como la raza / etnia. Esta situación ubicaría a algunos países y grupos sociales en el nuevo escenario poblacional de la STD, como en Uruguay (Cabella, 2009), o en regiones del interior de un país, como en Bogotá y Medellín para el caso colombiano (Flórez y Sánchez, 2013). En relación con los grupos sociales, el grado de incorporación al esquema de la STD es diferente para cada uno de los componentes que propone esta teoría. En la difusión de la cohabitación se observa un proceso de "abajo hacia arriba". En este con- 
texto tan diverso, los grupos de alta escolaridad han postergado la edad al primer hijo, y los sectores de bajos niveles educativos se encuentran en una etapa final de su primera transición demográfica (Esteve, García-Roman, Lesthaeghe y Lopez-Gay, 2012).

En relación con la separación conyugal, García y Rojas (2004) postulan que su aumento generalizado es uno de los componentes que más coincide con la formulación de la STD. Lo mismo afirman Flórez y Sánchez (2013) para el caso de Colombia, en donde se observó un incremento de las segundas o posteriores uniones. Sin embargo, la heterogeneidad tanto de las intensidades como de los calendarios de cada componente de la STD indica que los significados de estos cambios no son unívocos, y que los términos de la formación y la disolución de las uniones van a estar marcados por las desigualdades materiales y por la subordinación de las mujeres (García y Rojas, 2004).

La separación conyugal es un tema presente en los estudios generales sobre las transformaciones de las familias latinoamericanas, gran parte de los cuales fueron liderados por la CEPAL (véase Arriagada, 2007). En dichos trabajos se menciona este evento como sustrato contextual de ciertas condiciones de vulnerabilidad, como el aumento de los hogares monoparentales encabezados por mujeres (Arriagada, 2007); o también como expresión de cambios positivos de un orden sexual desigual "machista", en el cual la finalización de relaciones insatisfactorias no constituía una posibilidad para las mujeres (Jelin, 2007).

El significado atribuido al aumento de la disolución de las uniones es diferente cuando se tiene en cuenta la desigualdad económica. En los sectores con mejores ingresos, este incremento expresaría la independencia de las mujeres que toman esta decisión de forma autónoma en el sentido de la teoría de la STD, como se ha observado en México (Solís y Ferraris, 2014) o en las cohortes de mujeres más antiguas (1945-1956) de Uruguay (Bucheli y Vigna, 2005). Sin embargo, para los sectores más pobres que ya presentaban altos niveles de uniones consensuales antes del boom de la cohabitación (Esteve, Lesthaeghe y López-Gay, 2012), la disolución de las uniones pudo actuar como un mecanismo de respuesta ante las dificultades materiales experimentadas por los hogares.

Como se ha dicho, las diferentes posturas del debate sobre la STD en América Latina tienen puntos en común que reconocen la heterogeneidad de los cambios familiares y reproductivos en la región. Las diferencias más destacadas en torno a este debate se relacionan con las interpretaciones de estos procesos. Por un lado, están quienes conciben este cambio como un desarrollo progresivo que, con distintos ritmos y significados, llevaría a to- 
dos los grupos hacia una convergencia de sus pautas familiares y reproductivas (Cabella, 2009; Esteve, García-Roman, Lesthaeghe y Lopez-Gay, 2012; Flórez y Sánchez, 2013).

Por otro lado, se encuentran quienes critican esta perspectiva desarrollista por considerar que la búsqueda de regularidades y convergencias oscurece la tarea del investigador de descubrir la diversidad de significados e implicaciones que una misma condición cuantitativa puede tener para dos grupos diferentes. Por tanto, más que "encontrar" la STD en América Latina, los estudios deben orientarse al conocimiento empírico y a la explicación teórica de la diversidad demográfica de la región y sus senderos futuros (García y Rojas, 2004), prestando especial atención a los significados que estos cambios tienen para los distintos sectores sociales (Solís y Puga, 2009). Sin embargo, en relación con el estudio de la disolución de las uniones, algunos estudios advierten sobre las limitaciones de los instrumentos de investigación para capturar la dinámica real de la separación conyugal (García y Rojas, 2004; Goode, 1993), lo cual impediría la formulación de conclusiones definitivas en el debate sobre la STD en América Latina (Cabella, Peri y Street, 2005).

\section{Las separaciones conyugales como objeto propio de estudio}

Existe una serie de estudios centrados exclusivamente en analizar la disolución de las uniones como evento demográfico, sin resaltar su conexión con la fecundidad o como un elemento de validación de la teoría de la STD. Al respecto, destacan los trabajos pioneros de Noreen Goldman (1981) y sus tablas de vida para distintas duraciones en Colombia, Panamá y Perú, a partir de las historias de unión de la Encuesta Mundial de Fecundidad (EMF) de 1976-1977. En México, Norma Ojeda (1986) en su estudio "Separación y divorcio en México: una perspectiva demográfica”, utilizó tablas de vida para analizar la separación conyugal con datos de la EMF de 1976 y la sección mexicana de las encuestas PECFAL-Rural efectuadas en 1969 y 1970.

Aunque representativo solo a nivel urbano, el trabajo más completo sobre las separaciones y los divorcios es el de Zamudio y Rubiano (1991). En su libro Las separaciones conyugales en Colombia, las autoras estiman además el nivel y los diferenciales, y describen las características y condiciones de las uniones que terminan en separación a partir de una muestra de 5200 personas separadas, provenientes de 22111 hogares encuestados. Esta muestra se realizó con el propósito de conocer los problemas y conflictos en las distintas etapas de la ruptura, la utilización del marco legal, la 
reorganización posterior de los separados y su descendencia, su situación legal, y las opiniones en el momento de la encuesta sobre el matrimonio, el divorcio y la vida conyugal en general.

Después de la década de los ochenta, el interés académico por la disolución de las uniones decae hasta el inicio del nuevo siglo, cuando vuelve a emerger, pero esta vez como un objeto propio de estudio y no en relación con otros fenómenos demográficos. En este sentido, sobresalen los trabajos de Cabella $(1998 ; 2010)$ y de Bucheli y Vigna (2005) para Uruguay, quienes, a partir de los registros administrativos y de dos encuestas con historias de unión (Encuesta de Situaciones Familiares de 2001 y Encuesta de Género y Generaciones de 2004-2005), identifican los niveles, las tendencias y los diferenciales del divorcio. En México se encontraron trabajos similares. Ojeda y González (2008) comparan los cambios en los diferenciales de la primera disolución al contrastar las estimaciones basadas en la Encuesta Mundial de Fecundidad de 1976 con la Encuesta de Salud Reproductiva de 2003. Solís y Puga (2009) y Solís y Ferraris (2014) actualizaron el conocimiento del fenómeno en México, en conjunto con la formación de las uniones, en un intento por documentar las dos caras de la nupcialidad contemporánea. También sobresalen los estudios de Julieta Pérez Amador, quien mediante técnicas multiestado y multivariado, documenta los cambios en la formación y disolución de las parejas (Pérez Amador, 2008), y también en un trabajo más reciente, junto con Norma Ojeda, estudia los cambios en los factores predictivos de la disolución conyugal voluntaria (Pérez Amador y Ojeda, 2016).

En este grupo de trabajos destacan las aportaciones de Casique (2000) para Venezuela, con datos de la Encuesta de Fecundidad de 1991; y de Binstock (2004) para el área metropolitana de Buenos Aires, utilizando el módulo de historias de unión incluido en la Encuesta Anual de Hogares de 2002. En Costa Rica, Reuben, Fernández y Castillo (2013), basados en una muestra de sentencias de divorcio, desarrollaron una investigación centrada exclusivamente en estos eventos. Los hallazgos sobre las estimaciones y los diferenciales de la separación conyugal se presentan en los siguientes apartados.

En el marco del interés por la separación conyugal, identificamos una serie de estudios emergentes que exploran la vinculación entre la disolución de las uniones y su relación con la migración internacional. Si bien no constituye una narración propia, en el sentido de las narraciones anteriores, sí aparece como un grupo de investigaciones recientes que dan cuenta de los patrones de ruptura de la unión de los inmigrantes latinoamericanos en Estados Unidos y Europa; por tanto, se incluyen en la presente revisión a fin de tener un panorama actualizado del estado de la cuestión. 
Por una parte, existe un grupo de trabajos que estudian el efecto de la migración sobre la separación conyugal y sus consecuencias para el bienestar de los hijos. Al estudiar la ausencia del padre migrante en los hogares mexicanos, Nobles (2013) llama la atención sobre la importancia de incluir esta condición en el análisis de las transiciones familiares y de la inestabilidad de los hogares con sus respectivas consecuencias para los niños. De hecho, en México el porcentaje de niños que crecen sin un padre por razones de la migración (tanto interna como internacional) es similar al ocasionado por la separación conyugal (Nobles, 2013).

Aunque la migración de un padre no necesariamente implica una separación conyugal, la interacción de estos dos eventos incrementa la probabilidad de separación. En un estudio basado en el análisis de las historias de unión y las historias reproductivas, con datos del Mexican Migration Project (MMP), ${ }^{2}$ Frank y Wildsmith (2005) confirman que, a nivel individual, las personas con una trayectoria recurrente de emigración a Estados Unidos tienen más probabilidad de disolver sus uniones en comparación con quienes no lo hacen o lo hacen por una única vez. Una relación similar se encontró para el colectivo puertorriqueño (Landale y Ogena, 1995). Estos hallazgos apoyarían la hipótesis de la migración como un mecanismo de evasión del control social ejercido por las comunidades de origen, las que, a su vez, al tener contacto directo e indirecto con otras experiencias de separación conyugal, experimentarían una especie de flexibilización normativa de las pautas familiares en las comunidades de origen, incrementado así las probabilidades de disolver una unión (Frank y Wildsmith, 2005; Landale y Ogena, 1995).

El papel de la comunidad como factor mediador entre la migración y la separación conyugal también fue confirmado en el estudio de Frank y Wildsmith (2005), quienes hallaron que, más allá del efecto individual, los habitantes de las comunidades con niveles medios de migración tienen un riesgo mayor de disolver la unión que los que viven en zonas con baja emigración. Este hallazgo cuestiona el efecto de selección de la migración, en el sentido de que los individuos que migran tienen ciertas características que los hacen más propensos a disolver sus uniones, para explicar el mayor riesgo de separación conyugal entre los migrantes. A medida que las comunidades institucionalizan la movilidad internacional, todos los procesos

${ }^{2}$ E1 Proyecto sobre la Migración Mexicana (MMP) se creó en 1982 por un equipo interdisciplinario en México y Estados Unidos. Esta iniciativa ha permitido recolectar información social, económica y demográfica sobre el proceso migratorio de México hacia Estado Unidos. Toda la información del proyecto, incluyendo las bases de datos, se encuentra en: http://mmp. opr.princeton.edu/home-en.aspx (consulta: junio 4 de 2018). 
de intercambio de ideas -o como los llaman los autores, las "remesas sociales"- modificarían la estructura social hacia una mayor aceptación de la separación conyugal y, por ende, un incremento generalizado de las probabilidades de experimentar tal evento (Frank y Wildsmith, 2005).

Por otra parte, encontramos una segunda línea de trabajos que considera la población inmigrante como cierto tipo de experimento natural, en el que las teorías de la socialización, la selectividad, la disrupción y la asimilación se ponen a prueba para explicar las diferencias entre migrantes y nativos en relación con los niveles y factores de la separación conyugal de este grupo y sus descendientes. En Europa existen estudios al respecto en España (González-Ferrer, Hannemann y Castro-Martín, 2016), Reino Unido (Hannemann y Kulu, 2015) y Suecia (Andersson, Obucina y Scott, 2015). Para Estados Unidos identificamos dos publicaciones relevantes (Bean, Berg y Van Hook, 1996; Phillips y Sweeney, 2005). Con distintos énfasis y atendiendo a las particularidades de cada país de destino, esta serie de trabajos indaga las similitudes y diferencias en las dinámicas de conyugalidad (tipo de unión y formación o disolución de la misma) de los inmigrantes y su descendencia en comparación con la población nativa. Dichas diferencias dan cuenta de las particularidades de las condiciones y los procesos migratorios, incluyendo el impacto sobre las pautas familiares en el origen y el destino.

Los comportamientos familiares de los migrantes, incluyendo sus pautas reproductivas, se explicarían por medio de tres hipótesis: la socialización, la adaptación y la selección. La primera de ellas postula que, dada la diversidad de los sistemas de parentesco en el mundo, el riesgo de separación conyugal de los inmigrantes será similar al de sus países de origen, en donde vivieron durante la etapa de socialización. Por el contrario, la segunda de estas hipótesis postula que, como resultado de un proceso de adaptación de sus preferencias, los inmigrantes tendrán riesgos de disolución similares a la población nativa. Finalmente, la hipótesis de la selección propone que, aunque las probabilidades son similares entre ambas poblaciones, esto no ocurre por un cambio de sus preferencias, sino porque esta población en sí misma es un grupo altamente selectivo en términos del nivel de escolaridad, la ocupación, la movilidad social u otras peculiaridades de sus trayectorias de vida (Kulu y González-Ferrer, 2014).

Los hallazgos empíricos indican que, en comparación con la población nativa de España, los inmigrantes de Latinoamérica reportan un riesgo de separación conyugal 2.6 veces mayor, luego de controlar por la duración de la unión, la cohorte de nacimiento y el nivel educativo. Este riesgo adicional se mantiene cuando se incluye el tipo de unión entre las variables 
independientes, pero baja un poco, a 2.2 (González-Ferrer, Hannemann y Castro-Martín, 2016). En el caso de Suecia, cuando se toma como referencia la población nativa de dicho país, los inmigrantes de Centro y Sudamérica tienen un riesgo de disolución $88 \%$ más elevado, ubicando a este grupo en el cuarto lugar entre los colectivos con mayor riesgo, después de los estados postsoviéticos, el Cuerno de África e Irán (Andersson, Obucina y Scott, 2015).

En el estudio sobre el Reino Unido se incluyeron los inmigrantes del Caribe (Hannemann y Kulu, 2015). Para la cohabitación, las autoras realizaron un modelo de riesgos competitivos entre separación y matrimonio, encontrando que, respecto a los nativos (personas con ambos padres británicos), los caribeños de primera generación reportan un riesgo $52 \%$ más grande de separación conyugal. Para el modelo de la disolución de los matrimonios, este riesgo es aún mayor ( $89 \%$ ). Este comportamiento es heredado a las siguientes generaciones. Adicionalmente, el estudio modela la disolución de las segundas uniones, encontrando también en ellas que los caribeños de segunda generación reportan un riesgo de ruptura más elevado.

Dado el considerable peso de la migración mexicana entre el colectivo latinoamericano, los estudios sobre separación conyugal en Estados Unidos toman a la población de origen mexicano entre sus grupos de comparación, junto a la población negra no hispana y la blanca no hispana. En relación con la población mexicana, los estudios ponen a prueba el carácter "protector" de la cultura familista de este grupo, que presenta niveles de separación conyugal más bajos que los de la población blanca y de la población negra no hispana. Si bien este menor riesgo se confirma, existen diferencias importantes entre sus generaciones. En comparación con la población blanca no hispana, los inmigrantes de primera generación reportan un riesgo de separación conyugal mucho más bajo (más del 70\% menor), pero para las generaciones posteriores no se encontraron diferencias significativas (Bean, Berg y Van Hook, 1996; Phillips y Sweeney, 2005).

\section{Estimación del nivel de separación conyugal en América Latina}

La estimación de los niveles de las separaciones conyugales ha sido una constante en los trabajos de la región. De acuerdo con la naturaleza de las fuentes consultadas, se han ofrecido distintas medidas. A pesar de las limitaciones conceptuales y técnicas, existe un consenso entre los investigadores sobre el incremento generalizado de las rupturas de las uniones en América Latina (García y Rojas, 2004; Rossetti, 1991). 
Algunos trabajos se aproximan a través de la distribución poblacional del estado civil registrada por los censos de población o por las encuestas transversales. En Argentina, Sana (2001) utilizó el porcentaje de hombres y mujeres de catorce o más años que en los censos de población (entre 1947 y 1991) indicaron estar divorciados. En 1947 dicho valor alcanzaba el 0.5\%, y para 1991 ascendía a 3.8\%. En Colombia, Flórez y Sánchez (2013), utilizando los censos de población de 1964, 1973, 1985, 1993 y 2005, restringieron su estimación únicamente a las mujeres separadas, divorciadas o viudas para cuatro grupos quinquenales de edad entre los 20 y 39 años. Al tomar el segmento de 35 a 39 años, se observa un aumento del porcentaje entre $1964(7.0 \%)$ y 2005 (11.0\%), constatando así el incremento en la inestabilidad de las uniones, especialmente a partir de 1985 (Flórez y Sánchez, 2013).

Posteriormente, en una investigación basada en el censo argentino de 1991, se estima que $40.8 \%$ de las personas de 15 años o más se encontraba sin pareja en el momento del censo. De éstas, $27.1 \%$ alguna vez habían estado unidas y el resto (72.9\%) nunca lo había estado. Entre quienes sí habían estado unidos, $65 \%$ se declaraban viudos y $35 \%$ como personas con alguna unión disuelta voluntariamente. Entre estos últimos, $79.6 \%$ eran separados/as y la mayoría se encontraba en el rango de edad de 40 a 44 años, siendo 45.4 años la edad media de las mujeres y 48.2 la de los hombres. Así mismo, el estudio calculó las probabilidades de declararse en un estado de separación conyugal, las cuales son más elevadas para las mujeres de todos los grupos de edad, a excepción del grupo de 15 a 19 años. También estas probabilidades son más altas para los grupos de edad de 45 a 49 años y de 50 a 54 años en el caso de las mujeres. En los hombres corresponden a los grupos de 50 a 55 años y de 55 a 59 años (Masciadri, 2002).

Además del censo, los investigadores han usado otras fuentes de corte transversal, como las encuestas de hogares, de demografía y de salud. Éste es el caso de Colombia, en donde, con datos de la Encuesta Nacional de Hogares, Carmen Elisa Flórez (2004) estima la distribución de los hogares de acuerdo a la etapa del ciclo de vida del hogar y el estado civil del jefe del hogar, en siete ciudades principales en los años 1978, 1983, 1988, 1993, 1998 y 2003. Mientras en 1978 el porcentaje de hogares en la etapa I (con hijos menores de 12 años) y en los cuales el jefe del hogar se declaraba como persona separada o divorciada, era de 3.5\%, en 2003 llegaba a 8.3\%. En una etapa posterior del ciclo familiar, cuando el hijo mayor tenía entre 12 y 18 años, estos mismos valores ascendieron a 8.2 y $15.3 \%$ respectivamente. Estos incrementos se observan en todos los grupos de ingreso, con lo cual la autora afirma que en los últimos 25 años las separaciones conyugales presentan un aumento generalizado (Flórez, 2004). 
Este aumento de las separaciones conyugales lo confirma Flórez en un trabajo posterior, con datos transversales de la Encuesta Nacional de Demografía y Salud ${ }^{3}$ de los años 1990, 1995, 2000, 2005 y 2010. Al observar a las mujeres colombianas entre 35 y 39 años, encuentra que el porcentaje de separadas o divorciadas en 1990 era de $12.9 \%$, incrementándose progresivamente hasta alcanzar $18.8 \%$ en 2010 . Según la cohorte de nacimiento se constata el mismo patrón, pues a los 25-29 años el 26.1\% de las mujeres de la cohorte nacida entre 1961 y 1965 se encontraban separadas o divorciadas en el momento de la encuesta, mientras para la cohorte 1981-1985 este valor llegaba al 44.3\% (Flórez y Sánchez, 2013).

Otro grupo de investigaciones ha estimado el nivel de rupturas a partir de la información disponible en las estadísticas vitales. Con el fin de tener un panorama regional, García y Rojas (2004) retoman la recopilación sobre divorcios que desde 1951 ofrece el Anuario Demográfico de Naciones Unidas, y a partir de ellos calculan distintos indicadores que buscan dilucidar las tendencias y patrones en el interior de la región. En este sentido, identifican niveles diferenciados de disolución de las uniones, siendo mayores en los países del Caribe (en particular Cuba), algunos de América Central, y en Colombia, Venezuela y Uruguay. Entre los escenarios culturales e institucionales subyacentes a estos patrones se encuentran las raíces coloniales en la formación de la familia, la emigración masculina, la participación laboral de las mujeres y el acceso a la educación; así como los cambios en los marcos legales y políticos que facilitan el divorcio.

De manera similar, Cabella (1998) analiza la evolución del divorcio en Uruguay entre 1950 y 1995 a partir de los datos oficiales del Registro Civil. Mediante el indicador coyuntural de divorcialidad (ICD) ${ }^{4}$ evalúa los cambios en la intensidad del divorcio y establece tres periodos: a) 1950-1965, caracterizado por un comportamiento más o menos constante del ICD con valores entre 10 y $12 \%$; b) 1965-1985, en el cual se empieza a observar un crecimiento pausado (alrededor de 17\%), seguido de un breve periodo de declive en la década de los ochenta; y c) 1985-1995, marcado por un incremento vertiginoso del ICD que duplica los valores de la fase anterior, y que alcanza valores de $30 \%$ entre los matrimonios celebrados en el primer quinquenio de los noventa.

${ }^{3}$ La Encuesta Nacional de Demografía y Salud es la versión colombiana de las Demographic and Health Surveys (DHS)

${ }^{4}$ De acuerdo con la autora, el ICD es una "medición de naturaleza predictiva que se interpreta como el porcentaje de matrimonios constituidos en un año dado que eventualmente terminarán en divorcio, siempre y cuando las tasas de divorcio por duración observadas en ese mismo año se mantengan estables" (Cabella, 1998, p. 230). 
Además de las estadísticas vitales, existen trabajos que basan sus estimaciones en las sentencias de divorcio disponibles en las estadísticas judiciales de algunos países. Éste es el caso de Costa Rica, en donde a partir de los datos del Boletín Estadístico del Tribunal Supremo de Elecciones, Reuben, Fernández y Castillo (2013) analizan las duraciones y características de los divorcios entre 1998 y 2005. Si bien no ofrecen estimaciones puntuales sobre los niveles nacionales del divorcio, los datos les permiten constatar el aumento de éstos, al mismo tiempo que observan cierta estabilidad de los matrimonios en el mismo periodo.

El incremento del divorcio también se observa en la reducción del número de años promedio de los matrimonios. Aquellos celebrados en 1995 duraron en promedio 14.2 años y los de 2005 alcanzaron 13.2 años. Junto con el alto nivel de subregistro de esta fuente, los autores reconocen las limitaciones de su trabajo dado que se basa en frecuencias absolutas que no tienen en cuenta variables relevantes como la estructura por edad (Reuben, Fernández y Castillo, 2013). Una limitación adicional de las estadísticas judiciales es la exclusión de las rupturas matrimoniales que no derivan en un proceso judicial (Simó y Solsona, 2010).

Ante las limitaciones de los censos de población, de los registros civiles y/o la información administrativa (judicial o notarial) para captar la intensidad y el calendario de las separaciones conyugales, se han elaborado encuestas probabilísticas para registrar las historias de unión de la población. En general, los módulos en que se basan estas encuestas contienen información sobre el orden de la unión, su permanencia o no en el momento de la encuesta, los meses o años en que se formaron y se disolvieron, así como la causa de la ruptura (divorcio, separación o viudez). Los trabajos revisados en esta investigación se basan en encuestas con información retrospectiva. En tal medida, presentan limitaciones derivadas de la ausencia de datos referidos al momento de la ruptura (como, por ejemplo, la situación laboral de los miembros de la pareja en ese momento, etc.). Adicionalmente, estas encuestas sólo dan cuenta de agregados territoriales amplios por las restricciones de los tamaños muestrales.

Los datos que proveen este tipo de fuentes retrospectivas permiten calcular tablas de vida para estimar las separaciones conyugales en distintas duraciones. Al respecto, existe un consenso sobre la pertinencia de estos procedimientos en la estimación de la separación conyugal, especialmente en contextos de alta informalidad de las uniones (Goldman, 1981; Masciadri, 2002; Ojeda, 1986; Pérez Amador, 2008; Pérez Amador y Ojeda, 2016; Zamudio y Rubiano, 1991). 
Con datos de la EMF de 1976 y 1977, Goldman (1981) utilizó las historias de unión de las muestras de Colombia, Panamá y Perú para calcular las tablas de vida de las uniones de las mujeres en edad reproductiva (15 y 49 años), teniendo en cuenta el tiempo de exposición al riesgo de disolución. Se observó que Panamá tenía el mayor nivel de rupturas conyugales con $40.1 \%$ de disolución a los veinte años de duración, seguido de Colombia (26.6\%) y Perú (18.3\%). Entre los trabajos consultados en esta revisión no se identificaron estudios posteriores al año 2000 para estos tres países debido, en parte, a la ausencia de encuestas con este tipo de datos. En 1985, Zamudio y Rubiano (1991), mediante la aplicación de una encuesta retrospectiva en Colombia, confirmaron el aumento de la separación entre las cohortes más jóvenes. Los resultados de su estudio encontraron que, después de diez años de iniciada la unión, la generación de 1955 a 1959 tenía un nivel seis veces más alto que los nacidos entre 1905 y 1904, y dos veces más elevado que los valores de la generación de 1940 a 1944 (Zamudio y Rubiano, 1991).

México es uno de los países con mayor producción sociodemográfica en el estudio de la separación conyugal con enfoque biográfico. En este sentido destaca el trabajo pionero de Norma Ojeda, quien en 1986 publicó el estudio "Separación y divorcio en México: una perspectiva demográfica". Ojeda (1986) estimó que, en 1976, 15 de cada 100 primeras uniones terminaban en separación o divorcio luego de veinte años de duración. Al comparar sus resultados con el trabajo de Goldman (1981), la autora ubicó a México entre los países con mayor estabilidad conyugal, dado que Panamá, Colombia y Perú reportaron niveles de 40, 27 y 18\% respectivamente (Ojeda, 1986).

En un trabajo posterior, Ojeda y González, al comparar el nivel de separación conyugal entre 1976 y 2008, encontraron que en México se había dado un incremento, pero pequeño. En 1976, 11 de cada 100 uniones terminaban después de diez años de duración, y en 2003 este valor llegaba a 12 rupturas (Ojeda y González, 2008). Trabajos posteriores confirmaron el aumento sostenido de la disolución de las uniones en las cohortes más jóvenes (Gómez, 2011; Pérez Amador y Ojeda, 2016; Solís y Ferraris, 2014; Solís y Puga, 2009), especialmente a partir de las uniones formadas a partir de 1995 (Solís y Ferraris, 2014). ${ }^{5}$

Finalmente, nuestra búsqueda permitió adicionalmente identificar dos países que cuentan con estimaciones sobre separación también basados en

${ }^{5}$ El trabajo de Solís y Puga (2009) se basa en la Encuesta Nacional de la Dinámica de las Familias (Endifam) de 2005; el de Gómez (2011), en la Encuesta Nacional de la Dinámica Demográfica (Enadid) de 1997; el de Solís y Ferraris (2014), en la Enadid de 2009; y el de Pérez Amador y Ojeda (2016), en la Encuesta Demográfica Retrospectiva (Eder) de 2011. 
métodos biográficos: Uruguay y Argentina. En el primero destaca el trabajo de Wanda Cabella, quien estimó en 27.6 y $28.8 \%$ el porcentaje nacional de separación conyugal para mujeres y hombres respectivamente. Su estimación se hizo para la población de 15 a 59 años de la Encuesta de Situaciones Familiares de 2001 y la Encuesta de Género y Generación de 2004-2005 (Cabella, 2010). En el caso argentino, el trabajo de Georgina Binstock, utilizando la Encuesta Anual de Hogares de Buenos Aires de 2002, encuentra que $2.3 \%$ de las mujeres nacidas entre 1930 y 1935 habían disuelto su primer matrimonio después de diez años de duración. Este mismo indicador llegó a un valor de $21.0 \%$ para la cohorte 1965-1969, confirmando con ello el aumento del fenómeno entre las generaciones más jóvenes (Binstock, 2004).

Existe, por último, un estudio que contrasta el nivel de la separación conyugal entre las capitales de Argentina y Uruguay. Con datos de las Encuestas de Situaciones Familiares, ${ }^{6}$ la investigación señala que las mujeres de Montevideo presentan niveles más altos de separación conyugal, en comparación con las de Buenos Aires. Después de cinco años de haberse unido, $22 \%$ de las primeras habían disuelto la unión, en contraste con 13\% de las segundas (Cabella, Peri y Street, 2005).

\section{Diferenciales de la separación conyugal en América Latina}

El estudio de los diferenciales y factores asociados a la separación conyugal ha permitido, por un lado, documentar su asociación con distintas variables $\mathrm{y}$, por otro, observar el cambio de estas relaciones en el tiempo como resultado de las transformaciones en los patrones de formación familiar, de la respuesta a la mayor participación de las mujeres en la vida pública, de los procesos de individualización, y de la diversificación de las trayectorias familiares de la población. Tanto la teoría de la nueva economía del hogar, como la de la segunda transición demográfica, ven en estos cambios una tendencia hacia formas de socialización "menos familiares", caracterizadas por la progresiva "extinción" del matrimonio, la preferencia por pocos hijos y el aumento de la inestabilidad de las uniones (Esping-Andersen y Billari, 2015). Sin embargo, en relación con la separación conyugal, la investigación demográfica ha venido documentando cambios importantes en su dinámica contemporánea.

${ }^{6}$ En Buenos Aires la encuesta fue realizada en 1999 y en Montevideo en 2001 (Cabella, Pery y Street, 2005). 
Por ejemplo, la asociación positiva de la escolaridad con el divorcio empieza a revertirse en algunos países europeos, en donde son ahora las mujeres con mayor nivel educativo las que reportan las tasas de disolución más bajas (Härkönen y Dronkers, 2006). Lo mismo sucede con el empleo de la mujer como factor desestabilizador de las uniones. En países con políticas de conciliación familiar fuertes, el empleo pierde su relación positiva con el divorcio, llegando incluso a operar como elemento "protector" de la estabilidad conyugal (Härkönen, 2014). Estas transformaciones son resultado de los procesos de individualización contemporáneos y expresión de un cambio estructural asociado con el cambio de estatus de la mujer, relacionado con lo que Frances Goldscheider y sus colegas han denominado "la revolución del género" (Goldscheider, Bernhardt y Lappegård, 2015).

La revolución del género se asienta justamente en el cuestionamiento a la relación entre lo público y lo privado, que busca balancear de forma equitativa el reconocimiento social y la contribución que hombres y mujeres hacen en cada una de estas esferas. En esta reestructuración de los ejes y elementos de la reproducción social, los comportamientos "menos familiares" narrados por la segunda transición demográfica corresponderían a un estado intermedio que abriría paso a una etapa posterior de "más familia", en la cual las sociedades, y en particular los hombres, contribuirían con mayor trabajo a las tareas del cuidado. De esta manera, las personas materializarían sus preferencias por una vida en donde la familia ocupa un peso importante, tal como ha sido reportado desde hace varios años (Esping-Andersen y Billari, 2015; Goldscheider, Bernhardt y Lappegård, 2015).

Retomando el debate sobre la segunda transición demográfica en América Latina, merecería la pena preguntarse no sólo si los factores que inciden en las probabilidades de experimentar una separación conyugal son iguales a los europeos, sino también por los cambios que estos diferenciales podrían reportar, teniendo en cuenta las transformaciones de las sociedades latinoamericanas en los términos de la revolución del género, pero en un contexto de alta desigualdad social y de fuertes contrastes sociales.

Apelando a la expresión de "modernización y modernidad incompleta", acuñado por Irma Arriagada (2007) para caracterizar los cambios en la familia latinoamericana desde la segunda mitad del siglo XX, ¿podríamos hablar de una revolución de género, aún más incompleta que la europea, o podríamos hablar mejor de una "revolución fragmentada" fuertemente marcada por las desigualdades sociales? Una forma de aproximarnos a este debate es a través del estudio empírico de los diferenciales de la separación conyugal en América Latina. La presente sección constituye un esfuerzo por sistematizar los factores identificados en la literatura, así como los po- 
sibles cambios que éstos pudieran presentar. Para ello, presentaremos los diferenciales en tres grupos de variables: los factores individuales, las características de la unión que se disuelve, y los factores asociados al contexto en donde ocurren estas rupturas.

\section{Las características individuales}

Las características individuales hacen referencia a las particularidades sociodemográficas de los individuos involucrados en la relación. En este grupo se identifican tres tipos de diferenciales o factores: $a$ ) la edad y la cohorte de nacimiento; $b$ ) la edad a la unión y la diferencia de edad con la pareja; $c$ ) el nivel educativo, la experiencia laboral y los ingresos; y $d$ ) la adscripción y práctica religiosa.

Aunque la edad y la cohorte de nacimiento son conceptos estrechamente relacionados, se usa este último para dar cuenta de los elementos sociales y culturales compartidos por un grupo de personas nacidas en un mismo año o intervalo de tiempo. En el caso de las rupturas de las uniones, se prueba si las diferencias en términos de experiencias, recursos y expectativas entre las cohortes de nacimiento pueden afectar sus niveles de separación. En ese sentido, se confirma el mayor riesgo de disolución de las cohortes más jóvenes en todos los países analizados. Sin embargo, la consistencia de los resultados es heterogénea.

En Colombia, Panamá y Perú (Goldman, 1981; Zamudio y Rubiano, 1991) y en un trabajo de Argentina (Binstock, 2004) se emplearon tablas de vida para la estimación de las duraciones de las uniones disueltas, sin controlar la influencia de otras variables. Los resultados más consistentes (en donde sí se controla por otras características) para afirmar este incremento en las cohortes más jóvenes provienen de estudios de México (Gómez, 2011; Ojeda y González, 2008; Pérez Amador, 2008; Pérez Amador y Ojeda, 2016; Solís y Ferraris, 2014; Solís y Puga, 2009), Uruguay (Bucheli y Vigna, 2005; Cabella, 2010), y en menor medida Brasil (Miranda-Ribeiro, 1993) y Argentina (Santillán y Street, 2005).

Además del aumento de las disoluciones en las generaciones más jóvenes, también se han dado cambios de acuerdo a la edad en el momento de la unión y a la diferencia de edad entre los miembros de la pareja. En todos los trabajos revisados que incluyeron esta dimensión se constatan las mayores probabilidades de separación conyugal cuando la unión se hace a edades muy tempranas (Bucheli y Vigna, 2005; Cabella, 2010; Goldman, 1981; Miranda-Ribeiro, 1993; Ojeda, 1986; Ojeda y González, 2008; Pérez Ama- 
dor y Ojeda, 2016; Santillán y Street, 2005; Solís y Ferraris, 2014; Zamudio y Rubiano, 1991). Entre los grupos más jóvenes también hay diferencias. En México, durante la década del setenta, el porcentaje más alto de ruptura lo tenían las personas unidas antes de los 16 años (Ojeda, 1986). Después de los 30 años, la relación adoptó una forma de "U" invertida, con los riesgos más altos para el grupo de 18 a 24 años en comparación con el de 12 a 17 y 25 y más años (Pérez Amador y Ojeda, 2016). Por otra parte, en Colombia también se encontró que el riesgo vuelve a incrementarse en uniones formadas a partir de los 40 años de edad (Zamudio y Rubiano, 1991)

No sólo la edad individual se ha documentado como un factor vinculado a la disolución; también se ha estudiado el rol de la diferencia de edad entre los integrantes de la pareja como un elemento que afecta la duración de la unión. En 1985, en Colombia, Zamudio y Rubiano (1991) muestran cómo, a pesar de la progresiva reducción de la brecha en la edad a la primera unión entre hombres y mujeres, en términos de la separación conyugal se observa que la diferencia de edad es menor entre quienes disuelven su unión. Sin embargo, en este trabajo no se controló por otras variables relevantes como el tipo de unión o el nivel educativo.

Para el caso de Brasil, y a partir de los datos de una encuesta de $1984,{ }^{7}$ además de confirmar el menor riesgo cuando el hombre es mayor que la mujer, se encontró que el riesgo de disolución se incrementa cuando la mujer es mayor entre uno y dos años $(\mathrm{OR}=1.55)$, y de forma sustantiva $(\mathrm{OR}=8.16)$ cuando ella tiene más de dos años que él (Miranda-Ribeiro, 1993). Sin embargo, también se observa que este riesgo se ha venido reduciendo entre las generaciones, e incluso en algunos países esta diferencia no es significativa, como se confirmó para Uruguay con datos de 2001 (Bucheli y Vigna, 2005).

El nivel educativo ha sido un factor ampliamente estudiado en los análisis sobre la separación conyugal. En América Latina esta variable ha operado de distintas maneras según el país y el momento en que la escolaridad fue incluida como un factor diferenciador de la separación conyugal. Basados en datos de la Encuesta Mundial de Fecundidad (1976-1977), se encontró que las mujeres con educación primaria y más (el grupo de mayor escolaridad) tenían una proporción más elevada de uniones disueltas en la duración de 15 años en México (Ojeda, 1986) y Panamá (Goldman, 1981). Un comportamiento contrario se encontró para Colombia y Perú, en donde

${ }^{7}$ Los modelos Cox controlaron por edad a la unión, cohorte de nacimiento, escolaridad, tipo de unión, fecundidad preconyugal, región de residencia, número de hijos y edad del hijo menor (Miranda-Ribeiro, 1993). 
la mayor proporción fue reportada entre las mujeres con menor escolaridad (Goldman, 1981).

Durante las décadas del ochenta y del noventa, el mayor nivel de separación conyugal de los grupos con niveles más elevados de escolaridad aún se reportaba para Brasil (Miranda-Ribeiro, 1993) y México (Pérez Amador, 2008), a partir de encuestas realizadas en 1984 y 1997, respectivamente. Para México, la autora identificó que dicho efecto ocurría únicamente para las uniones provenientes de matrimonios, pero desaparecía en las uniones libres.

En Colombia, Zamudio y Rubiano (1991), con datos de una encuesta de 1985, identificaron un comportamiento en "U" de la separación conyugal, con los menores niveles para los estratos medios, ${ }^{8}$ y las tasas más altas en el estrato bajo-bajo (Zamudio y Rubiano, 1991). En Argentina (con datos de 1999) se confirma la inversión de la relación con la escolaridad. Mientras en la cohorte de unión de 1960-1979 las mujeres con estudios superiores reportaban un riesgo más alto que el resto de las categorías educativas, en las uniones iniciadas entre 1980 y 1999 la categoría "secundaria completa o superior incompleta" tenía un riesgo 36\% más alto que las mujeres con mayor escolaridad (Santillán y Street, 2005).

Con el advenimiento del nuevo siglo, la concentración del riesgo de separación conyugal en los niveles altos de escolaridad se mantiene en Uruguay (Bucheli y Vigna, 2005) y yéxico (Ojeda y González, 2008; Solís y Medina, 1996). Sin embargo, en los años posteriores, estos países están experimentando cambios en dicha relación. En Uruguay, con datos de 2004, ya no se observan diferencias significativas en el riesgo de disolución en los niveles de escolaridad (Cabella, 2010). Por su parte, los estudios recientes en México empiezan a mostrar señales de una inversión de la asociación, pues con una encuesta de 2011, Pérez Amador y Ojeda (2016) encontraron que, en comparación con las mujeres con estudios secundarios, las universitarias tienen un riesgo 43\% menor. En este sentido, las mismas autoras advierten que su trabajo incluye el estatus laboral, lo cual no se había considerado en los estudios previos, y por tanto se omitía este importante efecto mediador en la relación entre disolución y educación.

${ }^{8}$ El estudio no usa la variable escolaridad como proxy del nivel socioeconómico. En cambio, crearon una variable de estrato social con seis categorías: bajo-bajo, bajo, medio bajo, medio, medio-alto y alto. Dicha variable corresponde a un índice sumatorio de cuatro dimensiones: nivel educativo, tenencia de la vivienda, ocupación y estrato asignado por el organismo de las estadísticas oficiales del país (DANE) (Zamudio y Rubiano, 1991).

${ }^{9}$ Estimaciones a partir de la Encuesta de Situaciones Familiares (ESF) de 2001, con información de mujeres entre 25 y 54 años de Montevideo y su área metropolitana (Bucheli y Vigna, 2005, p. 9).

Estudios Demográficos y Urbanos, vol. 36, núm. 1 (106), enero-abril, 2021, pp. 291-325 
Las encuestas empleadas para el estudio de los factores o diferenciales de la separación generalmente tienen poca información sobre las condiciones o estados del individuo en el momento de la ruptura. La mayoría de las variables explicativas hacen referencia a las características en el momento de la encuesta. Éste es el caso del estatus laboral, que, en el debate de la revolución del género, daría cuenta del efecto de la incorporación de la mujer al mercado de trabajo. Para superar esta limitación, algunos estudios usan el proxy "alguna experiencia de trabajo fuera del hogar" o "haber trabajado antes de entrar en unión". Usando esta solución, se confirmó que, en el primer lustro de la década de 2000, en Uruguay y México las mujeres con experiencias laborales tenían mayor riesgo de separación conyugal (Cabella, 2010; Ojeda y González, 2008).

Con el fin de mejorar las aproximaciones al efecto del trabajo de la mujer sobre la ruptura de la unión, Casique (2000) tiene en cuenta el momento en que la mujer trabajó, tomando como referencia el inicio de la primera unión en el área metropolitana de Caracas. De esta manera, en comparación con las mujeres que no trabajaron, las que lo hicieron después de unirse tienen $63 \%$ más posibilidad de experimentar una ruptura, y si trabajaron durante los primeros cinco años de la unión, este riesgo es 2.07 veces más alto. Así, la autora destaca que no sólo el trabajo de la mujer afecta la estabilidad conyugal, sino que dicho riesgo es más alto en las etapas iniciales de la vida en pareja. En 2011, y con un instrumento que sí recolectaba el estatus laboral en el momento de la disolución, se confirmó el mayor riesgo reportado por las mujeres con trabajos asalariados en México pues, en comparación con ellas, las que no trabajan y las que lo hacían por cuenta propia o eran trabajadoras familiares sin pago tenían respectivamente 60 y $66 \%$ menores probabilidades de disolver sus uniones (Pérez Amador y Ojeda, 2016).

En los artículos revisados sólo dos incluyeron la adscripción religiosa como determinante de la separación conyugal. En Uruguay se encontró una relación negativa de dicha variable. En comparación con las mujeres que no reportan religión alguna, las que sí lo hacen tienen un riesgo de disolución $31 \%$ menor (Cabella, 2008). Para el caso argentino se consideró la regularidad de la práctica religiosa, observando que una frecuencia mayor se asocia con un incremento del riesgo, aunque en las uniones más recientes se diluye tal efecto (Santillán y Street, 2005). 


\section{Las características de la unión}

Además de los atributos individuales, la literatura de la región ha prestado particular interés a las características de la unión como rasgos que modifican las probabilidades de disolución. Este grupo de variables se define a partir de criterios de temporalidad e institucionalidad de los arreglos conyugales. El presente apartado hace un "inventario" de los factores relacionados con el "momento" en que se formaron las uniones, la institucionalidad de las mismas (unión libre, cohabitación prematrimonial y matrimonio), y las características de ellas en términos de fecundidad y edad de los hijos.

Los trabajos documentados muestran una preocupación constante por observar si los cambios que experimentan las sociedades influyen en el incremento de la separación conyugal de las uniones conformadas en tiempos recientes. Entre dichas transformaciones, los marcos legales tienen un rol importante al permitir la disolución legal de las uniones que, como vimos anteriormente, sólo fue posible a partir de la década del setenta para gran parte de los países latinoamericanos. Otro cambio importante es el cambio de estatus de la mujer a través de la progresiva incorporación al mercado laboral y sus ganancias en materia educativa. Todos estos ajustes generan adaptaciones estructurales y cambios en las subjetividades, expresados a su vez en el mayor riesgo de ruptura de las uniones actuales y la menor duración de las mismas.

Aunque es difícil desligar el efecto de la cohorte de nacimiento (el cual se desarrolló en el apartado anterior sobre las características individuales) del rol de la cohorte o promoción de la unión, en esta revisión se incluye en un apartado diferente, sólo con fines analíticos, reconociendo su relación intrínseca. De esta manera, los estudios que se aproximan a la disolución desde la cohorte de la unión confirman el aumento del riesgo de ruptura en Argentina (Santillán y Street, 2005), México (Solís y Ferraris, 2014) y Uruguay (Cabella, 2008).

La segunda dimensión considerada en este grupo de factores es la institucionalidad (casarse o no) de las uniones y su efecto sobre el riesgo de ruptura. Además de la importante participación de las uniones libres en los sectores pobres sobre el total de uniones, la región ha experimentado un aumento importante de este tipo de uniones en todos los sectores sociales, especialmente en los segmentos de mayor escolaridad (Esteve, Lesthaeghe y López-Gay, 2012). Ante este rasgo dual del sistema de nupcialidad latinoamericano (Castro-Martín, 2002) surge la inquietud sobre la fragilidad de las uniones consensuales en comparación con los matrimonios. Esta preocupación aún es vigente dado el incremento de las uniones libres, incluso en los sectores medios y altamente educados, en donde el matrimonio era común. 
Luego de confirmar la menor duración de las uniones libres en comparación con los matrimonios, Goldman (1981) afirma que estas uniones tienen un riesgo mucho más alto de disolución per se, es decir, tienen un carácter "inestable" más allá de la preferencia individual por esta forma de conyugalidad. Desde entonces, esta dimensión de la vida en pareja ha sido de amplio interés para los estudios regionales, que han encontrado un efecto similar en Argentina (Santillán y Street, 2005), Brasil (Miranda-Ribeiro, 1993), Colombia (Zamudio y Rubiano, 1991), México (Ojeda, 1986; Pérez Amador y Ojeda, 2016; Solís y Ferraris, 2014) y Uruguay (Cabella, 2010).

$\mathrm{Al}$ evaluar el riesgo de ruptura de las uniones que pasan de unión libre a matrimonio, la evidencia no es homogénea y muestra variaciones de acuerdo a los patrones de nupcialidad de los países de la región. En México, un país con bajos niveles de cohabitación, Solís y Ferraris (2014) identifican a las uniones que experimentan esta transformación con un riesgo similar a aquellas iniciadas directamente en matrimonio, incluso al comparar este factor en dos momentos del tiempo, 1976 y 2003 (Ojeda y González, 2008). Por otra parte, en países con mayor presencia de la cohabitación, como Uruguay, la evidencia es heterogénea. Si bien Bucheli y Vigna (2005) asocian esta experiencia con el aumento de las rupturas, Cabella (2010) afirma que no existen diferencias significativas en comparación con los matrimonios directos.

En relación con la asociación de los hijos con el riesgo de disolución de las uniones, los estudios encontrados se centran en tres variables: la presencia de hijos en el hogar, la edad de la madre en el momento de tener el primer hijo y la existencia de hijos previos a la unión disuelta. En el primer caso se observa que las parejas sin hijos reportan mayores probabilidades acumuladas de disolución de las uniones (Cabella, 2010), y que, aun controlando por variables sociodemográficas, cada hijo adicional reduce los riesgos de separación en $10 \%$ en las duraciones de ocho años para el caso de México (Solís y Ferraris, 2014). Este efecto estabilizador también se encontró en los trabajos de Pérez Amador (2008) y de Pérez Amador y Ojeda (2016), además de confirmarse una asociación similar durante los ochenta en Brasil (Miranda-Ribeiro, 1993), así como en Argentina a finales de los noventa (Santillán y Street, 2005).

Otro elemento de la relación entre fecundidad y separación conyugal es la existencia de hijos antes del matrimonio. Los datos de la EMF mostraron que existía una heterogeneidad considerable, pues mientras en países como Perú las proporciones de uniones disueltas son similares en todas las duraciones entre quienes sí los tuvieron y quienes no, en Colombia y Panamá la separación es más alta entre los que tuvieron hijos (Goldman, 1981). 
En México se halló un resultado similar a estos dos últimos países (Ojeda, 1986). En Brasil también se encontró un riesgo mayor para el mismo grupo e igualmente para quienes se casan para "legitimar" al hijo, tomando como referencia la descendencia concebida y nacida después de iniciada la unión (Miranda-Ribeiro, 1993).

\section{Zona de residencia}

Aunque los factores contextuales que inciden en las rupturas de las uniones no aparecen como un tema de interés en los estudios de la región, los esfuerzos se han centrado en documentar el papel que tiene el vivir en una zona rural o en una urbana sobre el evento de interés. Ya en los setenta se identificaba un nivel más alto de disolución en las zonas urbanas en Colombia, Panamá, Perú (Goldman, 1981) y México (Ojeda, 1986). En este último país, en 1997 aún las zonas urbanas reportan un riesgo más alto de ruptura, tanto para las uniones consensuales como para los matrimonios (Pérez Amador, 2008).

\section{Conclusiones}

Los trabajos analizados en la presente revisión confirman que, a diferencia de lo ocurrido en los años ochenta, en la actualidad se cuenta con un campo de estudios alrededor de las separaciones conyugales desde una perspectiva sociodemográfica. Gracias a estas investigaciones hay evidencia empírica sobre el aumento de la disolución de las uniones contemporáneas y de las variables que la explican (Binstock, 2004; Bucheli y Vigna, 2005; Cabella, 1998, 2008, 2010; Cabella, Peri y Street, 2005; Casique, 2000; Goldman, 1981; Gómez, 2011; Miranda-Ribeiro, 1993; Ojeda, 1986; Ojeda y González, 2008; Pérez Amador, 2008; Pérez Amador y Ojeda, 2016; Raimondi, 2005; Reuben, Fernández y Castillo, 2013; Santillán y Street, 2005; Dos Santos Marcondes, 2008; Solís y Ferraris, 2014; Solís y Medina, 1996; Solís y Puga, 2009; Zamudio y Rubiano, 1991).

Uno de los aportes de esta revisión fue la identificación de las tres narrativas que contextualizan las motivaciones y las condiciones espacio-temporales de la producción bibliográfica sobre la separación conyugal. Desde los estudios que exploran su asociación con la fecundidad hasta los análisis que toman la ruptura de las uniones como un tema propio de estudio, las investigaciones han documentado esta importante dimensión de la conyu- 
galidad que, por un lado, tiene un impacto en las formaciones familiares y en los mercados matrimoniales y, por otro, constituye una expresión de cambios sociales de mayor alcance, en donde el ingreso de las mujeres al mercado laboral y su mayor presencia en la esfera pública adquieren un protagonismo importante.

De acuerdo al país de análisis, se observa una concentración de estudios sobre la separación conyugal de México y Uruguay. Dichos trabajos incluso han traspasado las fronteras geográficas y generacionales para documentar no sólo las dinámicas de disolución de los inmigrantes mexicanos, sino también de sus descendientes nacidos en Estados Unidos. También se encontraron, en menor medida, investigaciones sobre Argentina y estudios aislados en Brasil, Colombia, Costa Rica, Perú y Venezuela, los cuales no llegan a constituir un campo consolidado en este tema. Entre los vacíos de la literatura destaca la ausencia de evidencia para otros países de la región, principalmente para Centroamérica, la Región Andina y Chile. De igual manera, son escasos los trabajos que comparan las dinámicas entre países o ciudades, a excepción de un estudio a partir de la Encuesta Mundial de Fecundidad de los años setenta, en el que se incluye a Colombia, Panamá y Perú (Goldman, 1981), y de otro que compara las ciudades de Buenos Aires y Montevideo (Cabella, Peri y Street, 2005).

Durante el periodo cubierto por la presente revisión se confirmó que los determinantes de las separaciones conyugales son dinámicos y cambian a lo largo del tiempo, como ha ocurrido con la escolaridad en Uruguay (Cabella, 2010), la edad a la unión en México (Pérez Amador y Ojeda, 2016), o la condición de homogamia en Brasil (Miranda-Ribeiro, 1993). De esta manera, la evidencia de la región muestra que variables como la escolaridad, la unión libre, los contextos urbanos, las edades tempranas a la unión, o las diferencias de edad con la pareja, aún son diferenciales que inciden en la separación conyugal.

La revisión también permitió identificar la ausencia de investigaciones que comparen la intensidad y los factores de la disolución de las parejas heterosexuales con los de las parejas conformadas por gays y lesbianas, especialmente cuando de manera progresiva los países de la región empiezan a reconocer el matrimonio igualitario, como sucedió en Argentina (2010), Brasil (2013), Uruguay (2013), México (2015) y Colombia (2016). Por otra parte, el artículo también presenta una limitación importante al centrarse en la medición de la disolución como un evento demográfico, dejando por fuera la recopilación de los trabajos que abordan las consecuencias de la separación conyugal tanto para los miembros de la pareja como para los hijos. En este sentido, ejercicios realizados en esta dirección brindan luces sobre 
las ventajas de adoptar el enfoque de la vulnerabilidad como herramienta conceptual en el estudio de las implicaciones de la separación conyugal (García y Solsona, 2011).

Por otra parte, en una región con altos niveles de violencia de género, sorprende la ausencia de estudios que analicen el impacto de este fenómeno sobre la separación conyugal, teniendo en cuenta los tipos de violencia, el momento en que inician las agresiones, o su conexión con otras variables como el trabajo de la mujer o su nivel educativo. No sólo el estudio de la violencia es relevante, también es importante contar con investigaciones sociodemográficas que tengan en cuenta el rol de las dinámicas conyugales, como el conflicto y la autopercepción de la calidad de la relación, en la disolución de las uniones. Relacionado con este punto, y considerando la progresiva incorporación de las encuestas del uso del tiempo por parte de las oficinas de estadística de los países latinoamericanos (Aguirre y Ferrari, 2014), una línea futura de trabajo en el estudio de la separación podría tender puentes entre estos dos campos, siguiendo los postulados de la revolución del género (Goldscheider, Bernhardt y Lappegård, 2015). Así se podría constatar de qué manera la redistribución del trabajo del cuidado se ha correspondido o no con la redistribución del trabajo productivo, y cuál ha sido su impacto sobre la disolución.

\section{Bibliografía}

Aguirre, R. y Ferrari, F. (2014). Las encuestas sobre uso del tiempo y trabajo no remunerado en América Latina y el Caribe. Caminos recorridos y desafios hacia el futuro. (Documento de Trabajo, núm. 122). Comisión Económica para América Latina y el Caribe, Naciones Unidas (Serie Asuntos de Género). Recuperado de http://repositorio.cepal. org/bitstream/handle/11362/5851/S1420397_es.pdf?sequence=9yis Allowed $=\mathrm{y}$

Andersson, G., Obucina, O. y Scott, K. (2015). Marriage and divorce of immigrants and descendants of immigrants in Sweden. Demographic Research, 33, 31-64. Recuperado de http://www.jstor.org/stable/26331979

Ariza, M. y Oliveira, O. (2001). Familias en transición y marcos conceptuales en redefinición. Papeles de Población, 7(28), 9-39. Recuperado de http://www.scielo.org.mx/pdf/pp/v7n28/v7n28a2.pdf

Arriagada, I. (2007). Familias y políticas públicas en América Latina. Una historia de desencuentros. Santiago de Chile: CEPAL / UNFPA. 
Bean, F. D., Berg, R. R. y Van Hook, J. V. W. (1996). Socioeconomic and cultural incorporation and marital disruption among Mexican Americans. Social Forces, 75(2), 593-617. Recuperado de http://www.jstor. org/stable/2580415

Binstock, G. (2004). Cambio en las pautas de formación y disolución de la familia entre las mujeres de la Ciudad de Buenos Aires. Población de Buenos Aires, 1(0), 8-15. Recuperado de http://www.redalyc.org/articulo. oa? id $=74010002$

Bucheli, M. y Vigna, A. (2005). Un estudio de los determinantes del divorcio en Uruguay. Desarrollo y Sociedad, 56, 1-21. Recuperado de http:// www.redalyc.org/articulo.oa?id=169114671001

Cabella, W. (1998). La evolución del divorcio en Uruguay (1950-1995). Notas de Población, 67/68, 209-245. Recuperado de https://repositorio. cepal.org/handle/11362/12681?locale-attribute=es

Cabella, W. (2008). Dissolução e formação de novas uniões: uma análise demográfica das tendências recentes no Uruguai. (Documento de Trabajo, núm. 56). Campinas, Brasil: NEPO. Recuperado de http://www. nepo.unicamp.br/publicacoes/textos_nepo/textos_nepo_56.pdf

Cabella, W. (2009). Dos décadas de transformaciones de la nupcialidad uruguaya. La convergencia hacia la segunda transición demográfica. Estudios Demográficos y Urbanos, 24(2), 389-427. Recuperado de https://estudiosdemograficosyurbanos.colmex.mx/index.php/edu/ article/view/1338/1331

Cabella, W. (2010). Los determinantes de la ruptura de la primera unión en el Uruguay: un análisis a partir de dos encuestas retrospectivas. Revista Latinoamericana de Poblacion, 4(7), 31-56. Recuperado de http:// www.redalyc.org/articulo.oa?id=323827303003

Cabella, W., Peri, A. y Street, M. C. (2005). Buenos Aires y Montevideo: ¿dos orillas y una transición? La segunda transición demográfica en perspectiva biográfica. En S. Torrado (ed.), Trayectorias nupciales, familias ocultas (Buenos Aires, entre siglos) (pp. 207-232). Buenos Aires: CIEPP / Miño y Dávila.

Casique, I. (2000). Trabajo femenino extradoméstico y riesgo de disolución de la primera unión. El caso de las mujeres urbanas en la región capital de Venezuela. Papeles de Población, 6(25), 35-57. Recuperado de http://www.redalyc.org/articulo.oa?id=11202503

Castro-Martín, T. (2002). Consensual unions in Latin America: Persistence of a dual nuptiality system. Journal of Comparative $\mathrm{Fa}$ mily Studies, 33(1), 35-55. Recuperado de http://digital.csic.es/ bitstream/10261/93121/1/2002_Castro_JComFamStudies.pdf 
Dos Santos Marcondes, G. (2008). Refazendo familias: trajetórias familiares de homens recasados. São Paulo, Brasil: Universidade Estadual de Campinas.

Downing, D. y Yaukey, D. (1979). The effects of marital dissolution and re-marriage on fertility in urban Latin America. Population Studies, 33(3), 537-547. Recuperado de https://www.jstor.org/stable/ 2173897?seq=1\#metadata_info_tab_contents

Ebanks, G. E., George, P. M. y Nobbe, C. E. (1974). Fertility and number of partnerships in Barbados. Journal Population Studies, 28(3), 449461. Recuperado de https://www.tandfonline.com/doi/abs/10.1080/00 324728.1974.10405192

Esping-Andersen, G. y Billari, F. C. (2015). Re-theorizing family demographics. Population and Development Review, 41(1), 1-31. Recuperado de https://onlinelibrary.wiley.com/doi/full/10.1111/j.1728-4457.2015.00 024.x

Esteve,A., García-Roman, J., Lesthaeghe, R. y López-Gay,A. (2012). The "second demographic transition" features in Latin America: The 2010 update. Inédito. Recuperado de https://www.researchgate.net/publication/ 258000744_The_Second_demographic_Transition_Features_in_ Latin_America_the_2010_update

Esteve, A., Lesthaeghe, R. y López-Gay, A. (2012). The Latin American cohabitation boom, 1970-2007. Population and Development Review, 38(1), 55-81. Recuperado de https://www.ncbi.nlm.nih.gov/ pubmed $/ 22833864$

Fernández, M. (2010). Estudio sobre las trayectorias conyugales de las mujeres del Gran Montevideo. Ciudad de México: Facultad Latinoamericana de Ciencias Sociales.

Fernández, M. (2017). La disolución de la primera unión y su relación con la fecundidad de las mujeres montevideanas. Revista Latinoamericana de Población, 11(21), 71-94. Recuperado de http://www.redalyc.org/ pdf/3238/323854675004.pdf

Flórez, C. E. (2004). La transformación de los hogares: una visión de largo plazo. Coyuntura Social, 30, 23-49. Recuperado de https://www. repository.fedesarrollo.org.co/handle/11445/1078

Flórez, C. E. y Sánchez, L. M. (2013). Fecundidad y familia en Colombia: ¿hacia una segunda transición demográfica? Bogotá, Colombia: Profamilia (Serie de Estudios a Profundidad de la Encuesta Nacional de Demografía y Salud, 1990-2010). Recuperado de https://www.minsalud. gov.co/sites/rid/Lists/BibliotecaDigital/RIDE/INEC/INV/0\%20-\%20 
SERIE\%20ESTUDIOS\%20A\%20PROFUNDIDAD\%20FINAL $\% 20$ WEB\%202014.pdf

Frank, R. y Wildsmith, E. (2005). The grass widows of Mexico: Migration and union dissolution in a binational context. Social Forces, 83(3), 919-947. Recuperado de http://www.jstor.org/stable/3598264

García, B. y Rojas, O. (2004). Las uniones conyugales en América Latina: transformaciones en un marco de desigualdad social y de género. Notas de Población, 78, 65-96. Recuperado de https://repositorio.cepal.org/ handle/11362/12761

García, T. y Solsona, M. (2011). El divorcio como nudo biográfico. Una revisión de la literatura reciente desde la perspectiva de la vulnerabilidad postdivorcio. Documents d'Analisi Geografica, 57(1), 105-126. Recuperado de https://www.raco.cat/index.php/DocumentsAnalisi/article/ view/241973/324564

Goldman, N. (1981). Dissolution of first unions in Colombia, Panama, and Peru. Demography, 18(4), 659-679. Recuperado de https://www.ncbi. nlm.nih.gov/pubmed/7308543

Goldscheider, F., Bernhardt, E. y Lappegård, T. (2015). The gender revolution: A framework for understanding changing family and demographic behavior. Population and Development Review, 41(2), 207-239. Recuperado de https://onlinelibrary.wiley.com/doi/full/10.1111/j.1728-4457. 2015.00045.x

Gómez, M. (2011). ¿Separación, divorcio o viudez? Cambios en la disolución de uniones conyugales de mujeres mexicanas. En J. Quilodrán (ed.), Parejas conyugales en transformación (pp. 167-210). Ciudad de México: El Colegio de México, A.C.

González-Ferrer, A., Hannemann, T. y Castro-Martín, T. (2016). Partnership formation and dissolution among immigrants in the Spanish context. Demographic Research, 35, 1-28. Recuperado de http://www. jstor.org/stable/26332069

Goode, W. J. (1993). World changes in divorce patterns. New Haven: Yale University Press.

Hannemann, T. y Kulu, H. (2015). Union formation and dissolution among immigrants and their descendants in the United Kingdom. Demographic Research, 33, 273-312. Recuperado de http://www.jstor.org/ stable/26331987

Härkönen, J. (2014). Divorce: Trends, patterns, causes, and consequences. En J. Treas, J. Scott y M. Richards (eds.), The sociology of families (pp. 303-322). Chichester: Wiley-Blackwell Press. 
Härkönen, J. y Dronkers, J. (2006). Stability and change in the educational gradient of divorce. A comparison of seventeen countries. European Sociological Review, 22(5), 501-517. Recuperado de https://www. researchgate.net/publication/237771668_Stability_and_Change_in the_Educational_Gradient_of_Divorce_A_Comparison_of_Seventeen_ Countries

Jelin, E. (2007). Las familias latinoamericanas en el marco de las transformaciones globales. En I. Arriagada (coord.), Familias y politicas públicas en América Latina. Una historia de desencuentros (pp. 93-124). Santiago de Chile: CEPAL / UNFPA.

Kulu, H. y González-Ferrer, A. (2014). Family dynamics among immigrants and their descendants in Europe: Current research and opportunities. European Journal of Population, 30(4), 411-435. Recuperado de https://link.springer.com/article/10.1007/s10680-014-9322-0

Landale, N. S. y Ogena, N. B. (1995). Migration and union dissolution among Puerto Rican women. The International Migration Review, 29(3), 671692. Recuperado de https://www.jstor.org/stable/2547499?seq=1\# metadata_info_tab_contents

Leone, T. y Hinde, A. (2007). Fertility and union dissolution in Brazil: An example of multi-process modelling using the demographic and health survey calendar data. Demographic Research, 17, 157-180. Recuperado de https://www.demographic-research.org/volumes/vol17/7/17-7. pdf

Lesthaeghe, R. (1995). The second demographic transition in western countries: An interpretation. En K. Oppenheim Mason y A. Jensen (eds.), Gender and family change in industrialized countries (pp. 17-62). Oxford: Clarendon Press.

Lesthaeghe, R. (2010). The unfolding story of transition. Population and Development Review, 36(2), 211-251. Recuperado de https://online library.wiley.com/doi/epdf/10.1111/j.1728-4457.2010.00328.x

Liu, C., Esteve, A. y Treviño, R. (2017). Female-headed households and living conditions in Latin America. World Development, 90, 311-328. Recuperado de https://www.sciencedirect.com/science/article/pii/S030 $5750 \times 15310093$

Masciadri, V. (2002). Tendencias recientes en la constitución y disolución de las uniones en Argentina. Notas de Población, 74, 53-110. Recuperado de https://repositorio.cepal.org/handle/11362/12725

Miranda-Ribeiro, P. (1993). Começar de novo: um estudo comparativo do descasamento e recasamento. Brasil: Universidade Federal de Minas Gerais. 
Nobles, J. (2013). Migration and father absence: Shifting family structure in Mexico. Demography, 50(4), 1303-1314. Recuperado de http://www. jstor.org/stable/42920555

Ojeda, N. (1986). Separación y divorcio en México: una perspectiva demográfica. Estudios Demográficos y Desarrollo Urbano, 1(2), 227265. Recuperado de https://estudiosdemograficosyurbanos.colmex.mx/ index.php/edu/article/view/588/581

Ojeda, N. (1989). El curso de vida familiar de las mujeres mexicanas. Cuernavaca, Mor.: Universidad Nacional Autónoma de México, Centro Regional de Investigaciones Multidisciplinarias.

Ojeda, N. y González, E. (2008). Divorcio y separación conyugal en México en los albores del siglo XXI. Revista Mexicana de Sociología, 70(1), 111-145. Recuperado de http://revistamexicanadesociologia.unam.mx/ index.php/rms/article/view/6120/5641

Onaka, A. T. y Yaukey, D. (1973). Reproductive time lost due to sexual union dissolution in San Jose, Costa Rica. Population Studies, 27(3), 457-465. Recuperado de https://www.jstor.org/stable/2173765?seq=1\# metadata_info_tab_contents

PérezAmador, J. (2008). Análisis multiestado multivariado de la formación y disolución de las parejas conyugales en México. Estudios Demográficos y Urbanos, 23(3), 481-511. Recuperado de https://estudiosdemograficos yurbanos.colmex.mx/index.php/edu/article/view/1319/1312

Pérez Amador, J. y Ojeda, N. (2016). Una nueva mirada a los factores predictivos de la disolución conyugal voluntaria en México. En M. L. Coubès, P. Solís y M. E. Zavala de Cosío (coords.), Generaciones, cursos de vida y desigualdad social en México (pp. 223-254). Ciudad de México: El Colegio de México, A.C. / El Colegio de la Frontera Norte. Phillips, J. A. y Sweeney, M. M. (2005). Premarital cohabitation and marital disruption among white, black, and Mexican American women. Journal of Marriage and Family, 67(2), 296-314. Recuperado de http:// www.jstor.org/stable/3600270

Quintín, P. (2008). Perspectivas sobre la conyugalidad. Una revisión bibliográfica.(DocumentosdeTrabajo, núm. 107).Cali:CIDSE. Recuperadode https://www.researchgate.net/publication/4829881_PERSPECTIVAS_ SOBRE_LA_CONYUGALIDAD

Raimondi, M. (2005). Consecuencias de la ruptura conyugal en las condiciones de vida de las mujeres (Área Metropolitana de Buenos Aires, finales del siglo XX). En S. Torrado (ed.), Trayectorias nupciales, familias ocultas (Buenos Aires, entre siglos) (pp. 169-206). Buenos Aires: CIEPP / Miño y Dávila. 
Reuben, S., Fernández, A. L. y Castillo, J. (2013). La duración media del matrimonio terminado en divorcio. Reflexiones, 92(2), 91-107. Recuperado de https://revistas.ucr.ac.cr/index.php/reflexiones/article/view/ $8770 / 8260$

Rosero-Bixby, L. (1978). Nupcialidad y fecundidad en cuatro zonas rurales de América Latina. (Documento de Trabajo, núm. 1008, Serie C). San José, Costa Rica: Celade. Recuperado de https://repositorio.cepal.org/ handle/11362/8493

Rossetti, J. (1991). Hacia un perfil de la familia actual en Latinoamérica y el Caribe. (Documento de trabajo, núm. 247). Santigo de Chile: Celade. Recuperado de https://repositorio.cepal.org/bitstream/handle/ 11362/9352/S9200134_es.pdf?sequence=1\&isAllowed $=\mathrm{y}$

Sana, M. (2001). La segunda transición demográfica y el caso argentino. $V$ Jornadas Argentinas de Estudios de Población (pp. 65-79). Buenos Aires, Argentina. Recuperado de https://www.academia.edu/1256222/ La_segunda_transici\%C3\%B3n_demogr\%C3\%A1fica_y_el_caso_ argentino

Santillán, M. M. y Street, M. C. (2005). La primera union y la ruptura conyugal en el curso de vida femenino. Algunas evidencias a partir de la ESF. En S. Torrado (ed.), Trayectorias nupciales, familias ocultas (Buenos Aires, entre siglos) (pp. 119-168). Buenos Aires: CIEPP / Miño y Dávila.

Simó, C. y Solsona, M. (2010). El registro estadístico de las rupturas de unión en España. Evaluación e ideas para avanzar desde la demografía. Papers. Revista de Sociología, 95(3), 609-632. Recuperado de https:// www.raco.cat/index.php/Papers/article/view/199156/266420

Solís, P. y Ferraris, S. (2014). Nuevo siglo, ¿nuevas pautas de formación y disolución de uniones? En C. Rabell (ed.), Los mexicanos. Un balance del cambio demográfico (pp. 269-305). Ciudad de México: Fondo de Cultura Económica.

Solís, P. y Medina, M. E. (1996). El efecto de la fecundidad sobre la disolución de uniones en México. Sociológica México, 32(11), 79-94. Recuperado de http://www.sociologicamexico.azc.uam.mx/index.php/ Sociologica/article/view/625/598

Solís, P. y Puga, I. (2009). Los nuevos senderos de la nupcialidad: cambios en los patrones de formación y disolución de las primeras uniones. En C. Rabell (ed.), Tramas familiares en el México contemporáneo. Una perspectiva sociodemográfica (pp. 179-198). Ciudad de México: El Colegio de México, A.C. / UNAM. 
Spijker, J. y Solsona, M. (2012). Atlas of divorce and post-divorce indicators in Europe. (Documento de Trabajo, núm. 412). Barcelona. Recuperado de http://citeseerx.ist.psu.edu/viewdoc/download?doi=10.1.1. 714.2077\&rep $=$ rep $1 \&$ type $=$ pdf

Van de Kaa, D. (2002). The idea of a second demographic transition in industrialized countries. Ponencia presentada en el Sixth Welfare Policy Seminar of The National Institute of Population and Social Security, Tokio, 29 de enero.

Zamudio, L. y Rubiano, N. (1991). Las separaciones conyugales en Colombia. Bogotá: Universidad Externado de Colombia.

\section{Acerca de los autores}

Fernando Ruiz-Vallejo es investigador postdoctoral de la Asociación Profamilia de Colombia. Es licenciado en Sociología por la Universidad Nacional de Colombia, maestro en Población y Desarrollo por la Facultad Latinoamericana de Ciencias Sociales (Flacso), sede México, y doctor en Demografía por la Universidad Autónoma de Barcelona. Ha sido docente e investigador de las universidades Pompeu Fabra y Autónoma de Barcelona. Actualmente forma parte del grupo de investigación de Profamilia del Ministerio de Ciencia, Tecnología e Innovación, donde desarrolla estudios sobre salud sexual y reproductiva, género, familia y envejecimiento, desde un enfoque de cursos de vida y desigualdades sociales. ORCID: https://orcid. org/0000-0003-1121-2562

Algunas de sus publicaciones recientes son:

Ruiz-Vallejo, F. (2019). La separación conyugal de las parejas del mismo sexo en Colombia. Revista Latinoamericana de Población, 13(24), 5-31. Recuperado de https://doi.org/10.31406/relap2019.v13.i1.n24.1 Ruiz-Vallejo, F. (2020). La separación conyugal en los censos y en las encuestas de demografía y salud en Colombia, 1951-2015. Sociedad y Economía, 39, 156-182. Recuperado de https://sociedadyeconomia. univalle.edu.co/index.php/sociedad_y_economia/\%20article $\% 20 /$ view $\% 20 / 7913$

Montserrat Solsona i Pairó es profesora titular del Departamento de Geografía de la Universidad Autónoma de Barcelona e investigadora asociada del Centro de Estudios Demográficos. Ha sido profesora invitada y conferencista en Brasil, Japón y Senegal, y ha realizado estancias de investigación en Estocolmo y París. Es licenciada en Economía por la Universidad 
de Barcelona, demógrafa por el Celade y doctora en Geografía Humana por la Universidad Autónoma de Barcelona. Sus temas de interés son las nuevas formas familiares, las relaciones de género, los derechos sexuales y reproductivos y la economía del bien común. Actualmente desarrolla investigaciones sobre el divorcio y la custodia compartida en España y específicamente en Cataluña. ORCID: https://orcid.org/0000-0002-5613-672X

Entre sus publicaciones recientes destaca el libro:

Solsona i Pairó, M., Ajenjo Cosp, M., Brullet Tenas, C. y Gómez Casillas, A. (2020). La custodia compartida en los tribunales. ¿Pacto de pareja? ¿Equidad de género? Barcelona: Icaria.

Recepción: 20 de febrero de 2019. Aceptación: 24 de junio de 2019. 
